\title{
Organic Enrichment, Physical Phase State, and Surface Tension Depression of Nascent Core-Shell Sea Spray Aerosols During Two Phytoplankton Blooms
}

Hansol D. Lee ${ }^{1}$, Holly S. Morris ${ }^{1}$, Olga Laskina ${ }^{1}$, Camille M. Sultana ${ }^{2}$, Christopher Lee ${ }^{3}$, Thilina Jayarathne ${ }^{1}$, Joshua L. Cox², Xiaofei Wang ${ }^{2}$, Elias S. Hasenecz, Paul J. DeMott ${ }^{4}$, Timothy H. Bertram $^{5}$, Christopher D. Cappa ${ }^{6}$, Elizabeth A. Stone ${ }^{1}$, Kimberly A. Prather ${ }^{2,3,7}$, Vicki $H$. Grassian $^{2,3}$, and Alexei V. Tivanski ${ }^{1 *}$

${ }^{1}$ Department of Chemistry, University of Iowa, Iowa City, IA 52242, USA.

${ }^{2}$ Department of Chemistry and Biochemistry, University of California at San Diego, La Jolla, CA 92093, USA.

${ }^{3}$ Scripps Institution of Oceanography, University of California, San Diego, La Jolla, CA 92037, USA.

${ }^{4}$ Department of Atmospheric Science, Colorado State University, Fort Collins, CO 80521, USA.

${ }^{5}$ Department of Chemistry, University of Wisconsin-Madison, Madison, WI 53706, USA.

${ }^{6}$ Department of Civil and Environmental Engineering, University of California, Davis, CA 95616, USA.

${ }^{7}$ Department of Nanoengineering, University of California, San Diego, La Jolla, CA 92093, USA.

PM2.5, and PM10-2.5 organic volume fraction measurements. The $\mathrm{PM}_{2.5}$ and $\mathrm{PM}_{10-2.5}$ organic volume fraction (OVF) results are based on daily filter samples collected for 3-6 hours and analyzed offline for organic carbon via a thermal optical analyzer and inorganic ions using ion chromatography with conductivity detection. ${ }^{1-2}$ Organic carbon (OC) was converted to organic matter (OM) using two OC/OM ratios: 1.8 for water soluble organic matter (WSOM) and 1.4 for water insoluble organic matter (WIOM) following Facchini et al. ${ }^{3}$ This conversion estimates the mass of $\mathrm{O}, \mathrm{H}, \mathrm{N}, \mathrm{S}, \mathrm{P}$ and other elements associated with organic molecules. In calculating $\mathrm{OM}$ mass fractions, assuming all $\mathrm{OM}$ is entirely water-soluble provides an upper-limit, whereas assuming all $\mathrm{OM}$ is water-insoluble provides a lower-limit. The $\mathrm{OM}$ mass estimates were converted to volume assuming a density of laminarin $\left(1.54 \mathrm{~g} \mathrm{~cm}^{-3}\right)$ and palmitic acid $\left(0.852 \mathrm{~g} \mathrm{~cm}^{-}\right.$ 
${ }^{3}$ ) for WSOM and WIOM, respectively, which have been previously highlighted as model SSA compounds. ${ }^{4}$ Inorganic mass comprised of sodium, potassium, magnesium, calcium, chloride, bromide, nitrate and sulfate was converted to volume assuming the density of sea salt $\left(2.06 \mathrm{~g} \mathrm{~cm}^{-}\right.$ $\left.{ }^{3}\right)$. It should be noted that mass not quantified in Jayarathne et al. ${ }^{5}$ was ignored for these bulk OVF calculations, including water, cations (e.g. ammonium, iron, aluminum) and anions (e.g. fluoride, iodide, carbonate). An upper and lower limit for $\mathrm{PM}_{2.5}$ and $\mathrm{PM}_{10-2.5}$ OVF was calculated and plotted in Figure S1 using the estimated WSOM and WIOM volumes with inorganic volume.

Due to lack of organic-identity sensitivity from AFM OVF volume-based measurements, the data was also compared against bulk OVF values derived from $\mathrm{PM}_{2.5}$ and $\mathrm{PM}_{10-2.5}$ based on organic carbon and inorganic ion mass concentrations from Jayarathne et al. ${ }^{5}$ Overall, $\mathrm{PM}_{2.5} \mathrm{OVF}$ results across the experiment range from 0.18 to 0.43 , which is in good agreement with the AFM single particle OVF data that ranges from 0.24 to 0.44 . The AFM results also agree well with previous works that quantified the OVF of SSAs collected in the same experiment and studied using scanning transmission x-ray microscopy, which reported OVF values of $\sim 0.25$ for the bloom 1 and $\sim 0.30$ for bloom $2{ }^{6} \mathrm{PM}_{2.5} \mathrm{OVF}$ ranges from a high of $0.39-0.47$ on day 12 to a low of 0.16 -0.21 on day 25 . Values are higher during the beginning of the bloom 1 and reach a maximum on day 12 , before the bloom 1 peak. OVF decreases after day 12 and varies less for the remainder of the experiment $(0.16-0.21$ to $0.26-0.34)$. During the bloom 1 , organics, which were more surface active and aliphatic-like, were further enriched. But, there is no evident trend during the bloom 2. During the bloom 2, oxygen rich organic species were more prevalent- these species are expected to be less surface active and consequently their enrichment and the corresponding OVF would be less. ${ }^{7} \mathrm{PM}_{10-2.5}$ shows significantly lower OVF compared to $\mathrm{PM}_{2.5}$ and exhibits even less variation across the mesocosm experiment $(0.02-0.03$ to $0.06-0.08)$, with no clear trends for either 
phytoplankton bloom. This could be attributed in part to differences in the dominant organic species present, where organic enrichment increases drastically with decreasing aerosol size. ${ }^{8}$

The difference observed between bulk $\mathrm{PM}_{2.5}$ OVF and AFM OVF on day 14 can likely be attributed to OVF variation in aerosol size of larger SSA in $\mathrm{PM}_{2.5}$. While $\mathrm{PM}_{2.5}$ contains all aerosol $<2.5$ microns in size and the number fraction is dominated by sub-micron particles, aerosol mass will be dominated by the larger super-micron particles. Since the calculated OVF measurements are based on mass, $\mathrm{PM}_{2.5} \mathrm{OVF}$ is likely to be less sensitive to the OVF variation found in smaller sub-micron particles that have greater organic enrichment.

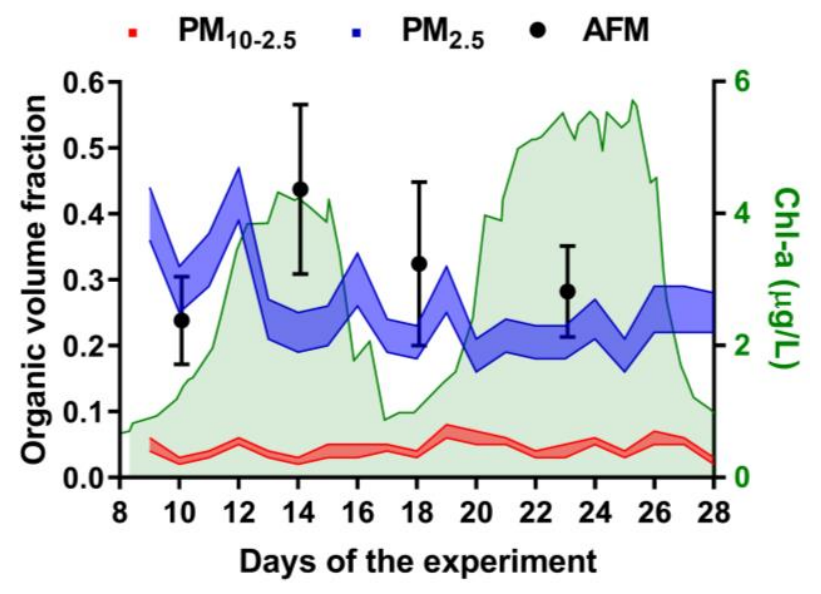

Figure S1. Temporal variation of single particle and bulk OVF results during IMPACTS 2014 study. Bulk PM10-2.5 and $\mathrm{PM}_{2.5}$ OVF values were calculated from organic carbon and inorganic ion mass concentrations taken from Jayarathne et al. ${ }^{5}$ The darker boundaries represent the upper and lower limits of the bulk OVF with the true value lying within the shaded region. AFM OVF averages are represented by black solid circles and error bars represent one standard deviation. Chlorophyll-a concentration is shown in green, which was taken from Wang et al. ${ }^{9}$ 


\section{REFERENCES}

1. Cavalli, F.; Facchini, M. C.; Decesari, S.; Mircea, M.; Emblico, L.; Fuzzi, S.; Ceburnis, D.; Yoon, Y. J.; O'Dowd, C. D.; Putaud, J. P.; Dell'Acqua, A., Advances in characterization of sizeresolved organic matter in marine aerosol over the North Atlantic. J Geophys Res-Atmos 2004, 109 (D24).

2. Jayarathne, T.; Stockwell, C. E.; Yokelson, R. J.; Nakao, S.; Stone, E. A., Emissions of Fine Particle Fluoride from Biomass Burning. Environmental Science \& Technology 2014, 48 (21), 12636-12644.

3. Facchini, M. C.; Rinaldi, M.; Decesari, S.; Carbone, C.; Finessi, E.; Mircea, M.; Fuzzi, S.; Ceburnis, D.; Flanagan, R.; Nilsson, E. D.; de Leeuw, G.; Martino, M.; Woeltjen, J.; O'Dowd, C. D., Primary submicron marine aerosol dominated by insoluble organic colloids and aggregates. Geophys Res Lett 2008, 35 (17).

4. Bertram, T. H.; Cochran, R. E.; Grassian, V. H.; Stone, E. A., Sea spray aerosol chemical composition: elemental and molecular mimics for laboratory studies of heterogeneous and multiphase reactions. Chem Soc Rev 2018, 47 (7), 2374-2400.

5. Jayarathne, T.; Sultana, C. M.; Lee, C.; Malfatti, F.; Cox, J. L.; Pendergraft, M. A.; Moore, K. A.; Azam, F.; Tivanski, A. V.; Cappa, C. D.; Bertram, T. H.; Grassian, V. H.; Prather, K. A.;

Stone, E. A., Enrichment of Saccharides and Divalent Cations in Sea Spray Aerosol During Two Phytoplankton Blooms. Environmental Science \& Technology 2016, 50 (21), 11511-11520.

6. Pham, D. Q.; O'Brien, R.; Fraund, M.; Bonanno, D.; Laskina, O.; Beall, C.; Moore, K. A.; Forestieri, S.; Wang, X. F.; Lee, C.; Sultana, C.; Grassian, V.; Cappa, C. D.; Prather, K. A.; Moffet, R. C., Biological Impacts on Carbon Speciation and Morphology of Sea Spray Aerosol. Acs Earth Space Chem 2017, 1 (9), 551-561.

7. Quinn, P. K.; Collins, D. B.; Grassian, V. H.; Prather, K. A.; Bates, T. S., Chemistry and Related Properties of Freshly Emitted Sea Spray Aerosol. Chem Rev 2015, 115 (10), 4383-4399.

8. Prather, K. A.; Bertram, T. H.; Grassian, V. H.; Deane, G. B.; Stokes, M. D.; DeMott, P. J.; Aluwihare, L. I.; Palenik, B. P.; Azam, F.; Seinfeld, J. H.; Moffet, R. C.; Molina, M. J.; Cappa, C. D.; Geiger, F. M.; Roberts, G. C.; Russell, L. M.; Ault, A. P.; Baltrusaitis, J.; Collins, D. B.; Corrigan, C. E.; Cuadra-Rodriguez, L. A.; Ebben, C. J.; Forestieri, S. D.; Guasco, T. L.; Hersey, S. P.; Kim, M. J.; Lambert, W. F.; Modini, R. L.; Mui, W.; Pedler, B. E.; Ruppel, M. J.; Ryder, O. S.; Schoepp, N. G.; Sullivan, R. C.; Zhao, D. F., Bringing the ocean into the laboratory to probe the chemical complexity of sea spray aerosol. P Natl Acad Sci USA 2013, 110 (19), 75507555 .

9. Wang, X. F.; Sultana, C. M.; Trueblood, J.; Hill, T. C. J.; Malfatti, F.; Lee, C.; Laskina, O.; Moore, K. A.; Beall, C. M.; McCluskey, C. S.; Cornwell, G. C.; Zhou, Y. Y.; Cox, J. L.; Pendergraft, M. A.; Santander, M. V.; Bertram, T. H.; Cappa, C. D.; Azam, F.; DeMott, P. J.; Grassian, V. H.; Prather, K. A., Microbial Control of Sea Spray Aerosol Composition: A Tale of Two Blooms. Acs Central Sci 2015, 1 (3), 124-131. 